\title{
Mast Cell Degranulation Induced by Type 1 Fimbriated Escherichia coli in Mice
}

\author{
Ravi Malaviya, * Elaine Ross, ${ }^{*}$ Barbara A. Jakschik, ${ }^{8}$ and Soman N. Abraham ${ }^{\star \star}$ \\ * Department of Pathology, Jewish Hospital of St. Louis, and ${ }^{\ddagger}$ Departments of Pathology and Molecular Microbiology and ${ }^{\S}$ Department \\ of Molecular Biology \& Pharmacology, Washington University School of Medicine, St. Louis, Missouri 63110
}

\begin{abstract}
The strategic location of mast cells at the host-environment interface and their ability to release potent mediators of inflammation have suggested that these cells may play a pivotal role in host defense against bacterial infection. The ability of the opportunistic pathogen, Escherichia coli, to induce degranulation of mast cells obtained from the mouse peritoneum was investigated. We determined that unlike a mutant derivative deficient in the FimH subunit of the fimbriae or nonfimbriated $E$. coli, type 1 fimbriated $E$. coli induced mast cell degranulation in vitro. The magnitude of mast cell degranulation was directly proportional to the number of adherent bacteria on the cell surface in the initial period of the interaction. Using a mouse model of bacterial peritonitis, we demonstrated mast cell degranulation and histamine release by type 1 fimbriated bacteria in vivo. Furthermore, beads coated with FimH but not with FimA, the major subunit of type 1 fimbriae, evoked mast cell release of histamine in vivo in amounts comparable to that elicited by type 1 fimbriated $E$. coli. These studies reveal that mast cells can be degranulated by interaction with type 1 fimbriated $E$. coli and that FimH, the mannose-binding component of the fimbriae, is a potent mast cell stimulant. (J. Clin. Invest. 1994. 93:1645-1653.) Key words: histamine • inflammation • host defense $\bullet$ FimH $\bullet$ bacterial adherence
\end{abstract}

\section{Introduction}

Bacterial infections are accompanied by a rapid and vigorous cascade of inflammatory reactions in the host. Currently, there is limited information on how this inflammatory process is initiated or which host cells are involved. One cell that has the potential to play a pivotal role in the pathogenesis of bacterial infections is the mast cell. These are a heterogeneous group of cells that are derived from hematopoietic precursors. Mast cells are preferentially localized at mucosal surfaces, skin, and around blood and lymphatic vessels, which are also common sites of entry for pathogenic bacteria. Mast cells have the capacity to release a variety of biologically active molecules such as products of arachidonic acid oxidation, histamine, cytokines, proteases, etc. (1), which could potentially affect the rate and intensity of the inflammatory reactions to bacteria. Although mast cells are well known for their role in type 1 hypersensitiv-

Address correspondence to Soman N. Abraham, Ph.D., Department of Pathology, Jewish Hospital of St. Louis, Washington University Medical Center, 216 South Kingshighway, St. Louis, MO 63110.

Received for publication 24 August 1993 and in revised form 6 December 1993.

J. Clin. Invest.

(C) The American Society for Clinical Investigation, Inc.

0021-9738/94/04/1645/09 \$2.00

Volume 93, April 1994, 1645-1653 ity reactions, other functions have been suggested. Galli and Kitamura (2) have presented a comprehensive review on the role of mast cells in various biological processes. These investigators have demonstrated mast cell involvement in leukocyte infiltration, edema, and fibrin deposition in inflammation resulting from substance $P$ and phorbol myristate acetate $(3,4)$. We have previously shown the role of mast cells in modulating immune complex mediated inflammation (5-8). Other studies have implicated mast cells in a variety of inflammatory conditions such as osteo- and rheumatoid arthritis, systemic lupus erythematosus, and mixed connective tissue disorders (1).

The ability of several species of bacteria to elicit mast cell release of histamine was investigated recently $(9,10)$. Although many bacterial species displayed stimulatory capacity, the more potent activators of mast cells were bacterial species in the family Enterobactericeae (9). Enterobacteria are noted for their surface expression of hairlike organelles of adhesion called fimbriae (or pili). One of the most commonly expressed fimbriae is type 1 fimbriae, which are characterized by their ability to recognize and bind D-mannose-containing compounds $(11,12)$. Type 1 fimbriae on enterobacteria, such as Escherichia coli, facilitate bacterial adherence to mannosylated residues on epithelial cells lining the various mucosal surfaces of the host, thereby enabling these organisms to establish a foothold in the host $(11,13)$. We have shown that type 1 fimbriae promote bacterial binding and activation of different immunoinflammatory cells such as lymphocytes and neutrophils, evoking a variety of biological reactions in the activated cells $(14,15)$. The determinant of adherence and host cell activation on type 1 fimbriae is a minor protein, FimH, which is located in a functionally competent configuration at the tips of each fimbrial filament (16-19).

We observed recently that type 1 fimbriae greatly facilitated the association of $E$. coli to bone marrow-derived mouse mast cells (20). This interaction resulted in phagocytosis and killing of adherent bacteria by the mast cells. Mast cell bactericidal activity was associated with acidification of phagocytic vacuoles and the release of toxic superoxide anions (20). By using a FimH $^{-}$mutant, we demonstrated that mast cell activation by type 1 fimbriated $E$. coli was mediated by FimH. Since the mast cells are primarily noted for their capacity to release various inflammatory mediators, we investigated in this study if mast cells were degranulated after exposure to type 1 fimbriated $E$. coli. Connective tissue mast cells provide a better model than bone marrow-derived cells for the study of mast cell degranulation; therefore, we used the former in these studies. Through in vitro and in vivo experiments, we showed that mast cells were degranulated upon exposure to type 1 fimbriated, but not to the FimH ${ }^{-}$mutant or nonfimbriated $E$. coli. Further, we showed that mast cell degranulation by type 1 fimbriated $E$. coli correlated at least in part with the adherence of the bacteria to the mast cell. The determinant on type $1 \mathrm{fim}-$ briae responsible for mast cell degranulation and histamine release was FimH, the mannose-binding subunit. 


\section{Methods}

\section{Materials}

Male CBA/J mice were obtained from Harlan Laboratories (Indianapolis, IN). Gelatin, BSA, glucose, $\alpha$-methyl D-mannopyranoside (MMP), ${ }^{1}$ and metrizamide were purchased from Sigma Chemical Co. (St. Louis, MO). Avidin-FITC was obtained from Zymed Laboratories, Inc. (San Francisco, CA), PBS and RPMI 1640 were from the Tissue Culture Support Center of Washington University (St. Louis, MO). Carboxylated beads were supplied by Polysciences Inc. (Warrington, PA).

\section{Bacterial strains and culture conditions}

E. coli ORN103(thr-1 leu-6 thi-1 $\Delta($ argF-lac $) U 169 x y l-7$ ara-13 mtl-2 gal-6 rpsL tonA2 fhuA2 minA $\min B$ recA13 $\delta($ fimABCDEFGH) (17, 21 ) (kindly furnished by Paul Orndorff, North Carolina State University, Raliegh, NC) is a nonfimbriated K-12 strain that was used as the host strain for the introduction of plasmids pSH2, pUT2002, pRT4, or pJP4. Plasmid pSH2 contains a segment of chromosomal DNA with the type 1 fim locus cloned from a clinical isolate of $E$. coli (22). This plasmid encodes all of the genes necessary for the expression of functional $E$. coli type 1 fimbriae. Plasmid pUT2002 is a derivative of $\mathrm{pSH} 2$ created by deleting a 1.2-kb Pvull fragment containing the entire fim $H$ gene (23). Plasmid pRT4 was subcloned from $\mathrm{pSH} 2$ and contains only the fimH gene (15). Plasmid pJP4 encodes the E. coli type 1 fimbrial chaperone, FimC $(15,24)$. The properties of each of these plasmids have been described in detail elsewhere $(15,17,21-24)$. For best expression of fimbriae, strain ORN103 was grown in Luria broth under static conditions for $18 \mathrm{~h}$. To maintain plasmids pSH2 or pUT2002 in the host, $40 \mu \mathrm{g}$ of chloramphenicol $/ \mathrm{ml}$ was incorporated into the medium. To maintain both plasmids pRT4 and pJP4 in the host, $50 \mu \mathrm{g}$ each of ampicillin and kanamycin was incorporated into the growth medium.

\section{Purification of FimH}

Recombinant FimH was stabilized and isolated from $E$. coli ORN103(pRT4)(pJP4) as recently described $(15,24)$.

\section{Preparation of FimA}

FimA was obtained by dissociating fimbriae isolated from the $\mathrm{FimH}^{-}$ mutant $E$. coli ORN103(pUT2002). Isolated fimbriae prepared as described previously $(23,25)$ were dissociated by exposure to saturated guanidine-hydrochloride for $16 \mathrm{~h}$. Guanidine hydrochloride was removed by dialysis against Tris- $\mathrm{HCl}$ buffer, $\mathrm{pH} 8$, containing $20 \mathrm{mM}$ EDTA at $4^{\circ} \mathrm{C}$ for $18 \mathrm{~h}$. The fimbrial subunits were prevented from reassembly by the presence of EDTA (25). This FimA preparation was determined to be $>85 \%$ pure based on SDS-PAGE.

\section{Covalent coupling of FimH and FimA to beads}

FimH or FimA ( $500 \mu \mathrm{g})$ was covalently coupled to carboxylated beads $(0.21 \mu \mathrm{m}$ in diameter) (Polysciences Inc) using a coupling procedure and a kit supplied by Polysciences Inc.

\section{Purification of mast cells}

Mast cells were isolated from peritoneal washings of male CBA/J mice. Peritoneal cells were harvested from mice in calcium- and magnesiumfree Tyrode's buffer containing $0.1 \%$ gelatin, $5 \mathrm{mM}$ Hepes, and $5 \mathrm{mM}$ morpholino ethanesulfuric acid. The suspension of cells was layered over a $22.5 \%$ metrizamide gradient and centrifuged at $450 \mathrm{~g}$ according to the method of Sterk and Ishizaka (26). The resulting preparation was found to consist of $>98$ percent mast cells.

\section{In vitro bacterial adherence to mast cells}

Purified peritoneal mast cells were suspended in RPMI- 1640 containing $15 \mathrm{mM}$ Hepes and $0.75 \%$ BSA to a concentration of $0.8 \times 10^{6} / \mathrm{ml}$.

1. Abbreviation used in this paper: MMP, $\alpha$-methyl D-mannopyranoside.
E. coli ORN103(pSH2), E. coli ORN103(pUT2002) or E. coli ORN103 were added to the mast cell suspension to a final concentration of $4 \times 10^{7} / \mathrm{ml}$ and the mixture was incubated at $37^{\circ} \mathrm{C}$. At appropriate intervals thereafter, small aliquots were taken out, and the mast cells were washed three times by differential centrifugation to remove unbound bacteria. The final pellet of mast cells were resuspended in buffer and cytospun on glass slides. The smears were fixed in Carnoy's fixative for $1 \mathrm{~min}$ and stained with crystal violet. At least 100 mast cells were examined for adherent bacteria by light microscopy.

\section{Assessment of mast cell degranulation}

In vitro assays. Purified mast cells $\left(0.8 \times 10^{6} / \mathrm{ml}\right)$ were exposed to $E$. coli ORN103(pSH2), E. coli ORN103(pUT2002), or E. coli ORN103 (final concentration of $4 \times 10^{7} / \mathrm{ml}$ ) for $1 \mathrm{~h}$ at $37^{\circ} \mathrm{C}$. Spontaneous granule release was assessed in parallel samples incubated with buffer alone. At appropriate time intervals, $0.2-\mathrm{ml}$ aliquots were taken out from the test mixture, as well as from the control tube, and the sample was cytospun onto glass slides. The smears were fixed in Carnoy's fixative and stained with avidin-FITC $(6.25 \mu \mathrm{g} / \mathrm{ml})$ for $2 \mathrm{~h}$. Avidin is known to bind selectively and quantitatively to heparin in mast cell granules. The avidin-FITC-stained smears were washed three times with PBS and then mounted in buffered glycerol containing 30 $\mathrm{mM}$ triethylenediamine $\mathrm{pH} 8.6(27,28)$. Smears were examined under ultraviolet illumination with an epifluorescent microscope (Labophot; Nikon, Tokyo, Japan). Granule content of mast cells were evaluated by measuring the fluorescence intensity (expressed in arbitrary units per mast cell) with an image analysis system (Microcomp; Southern Micro Instruments, Atlanta, GA). A significant decrease in fluorescence intensity of mast cell as compared to controls (PBS-treated) was interpreted as degranulation of mast cells.

In vivo assays. The peritoneal cavity is a convenient site to study mast cell degranulation in vivo. We have previously demonstrated peritoneal mast cell degranulation in mice induced by immune-complexes (5). Based on this model, we have developed a model of bacterial peritonitis to investigate bacteria induced mast cell degranulation. Peritonitis was induced in mice by intraperitoneal administration of 5 $\times 10^{6}$ bacteria, or an approximately equal number of FimH- or FimAcoated beads suspended in $0.5 \mathrm{ml}$ of PBS or PBS containing $200 \mathrm{mM}$ MMP. Control mice were injected with $0.5 \mathrm{ml}$ of PBS. After $60 \mathrm{~min}$, the mice were decapitated, and their peritoneal cavity was lavaged with $2 \mathrm{ml}$ of PBS containing $0.75 \%$ BSA. Peritoneal cells were sedimented by centrifugation at $400 \mathrm{~g}$ for $10 \mathrm{~min}$, and the cells were resuspended in PBS- $0.75 \%$ BSA and cytospun onto glass slides. The smears were fixed in Carnoy's fixative and then stained with avidin-FITC as described above.

Assessment of bacterial adherence to mast cells in vivo Mice were injected with $5 \times 10^{6}$ E. coli ORN103( $\mathrm{pSH} 2$ ) suspended in $0.5 \mathrm{ml}$ of PBS. After $15 \mathrm{~min}$, the mice were decapitated and their peritoneal cavity was lavaged with $2 \mathrm{ml}$ of PBS containing $0.75 \%$ BSA. Peritoneal cells were sedimented by centrifugation at $400 \mathrm{~g}$ for $10 \mathrm{~min}$, and the cells were resuspended in PBS- $0.75 \%$ BSA and cytospun onto glass slides. The smears were fixed in Carnoy's fixative and then stained with crystal violet stain. The percent of mast cells with at least one adherent bacteria was determined.

\section{Assessment of cell population in the peritoneal lavage of mice}

Mice were injected with $5 \times 10^{6}$ E. coli ORN103(pSH2) or FimH beads suspended in $0.5 \mathrm{ml}$ of PBS. After $60 \mathrm{~min}$, the mice were decapitated and their peritoneal cavity was lavaged with $2 \mathrm{ml}$ of PBS containing $0.75 \%$ BSA. Peritoneal cells were sedimented by centrifugation at $400 \mathrm{~g}$ for $10 \mathrm{~min}$, and the cells were resuspended in PBS- $0.75 \%$ BSA and cytospun onto glass slides. The smears were fixed in Carnoy's fixative and were stained with Wright's stain for differential cell count. The percent of mast cells, neutrophils, and monocytes/lymphocytes was determined from examining 1,000 peritoneal cells. 


\section{Histamine assays}

Histamine content was assessed by fluorimetric analysis using 0 -phthalaldehyde (29).

\section{Statistical analysis}

Values are expressed as mean \pm SEM. Significance of the difference between values was tested by Student's $t$ test.

\section{Results}

Mast cell degranulation induced by type 1 fimbriated E. coli. Type 1 fimbriated $E$. coli have been shown previously to induce a variety of biological reactions in various inflammatory host cells including human B lymphocytes and neutrophils $(14,15)$. To assess whether mast cell degranulation can be induced by type 1 fimbriated $E$. coli, connective tissue mast cells isolated from mouse peritoneum were exposed to a recombinant $E$. coli strain ORN103(pSH2) expressing cloned genes encoding for type 1 fimbriae. The degranulation of the mast cells was assessed by examining their fluorescence intensity using avidin-FITC as a probe. Avidin-FITC specifically binds to heparin, the major proteoglycan in the granules of connective tissue mast cells (28), and thus serves as a useful indicator of mast cell degranulation. The utility of this technique in demonstrating mast cell degranulation has previously been shown by us in immune-complex mediated peritonitis and reverse passive Arthus reactions in mice $(6,8)$. We showed that $E$. coli ORN103( $\mathrm{pSH} 2$ ), when incubated with mast cells at a ratio of $50: 1$, triggered a significant amount of mast cell degranulation. The fluorescence intensity of both a fully granulated and partially degranulated mast cell after exposure to bacteria when viewed through an image analysis system is shown in Fig. 1. Because totally degranulated cells could not be detected by this technique, it is noteworthy that our assessment of mast cell degranulation may be an underestimation.

To determine if type 1 fimbriae were responsible for the $E$. coli-mediated mast cell degranulation, we compared the fluorescence intensity of mast cells exposed to the type 1 fimbriated $E$. coli clone ORN103(pSH2) and to the nonfimbriated host strain $E$. coli ORN103. Compared to mast cells exposed to either nonfimbriated $E$. coli ORN103 $(175 \pm 21)$ or buffer $(188 \pm 8)$, the fluorescence intensity of mast cells exposed to type 1 fimbriated $E$. coli ORN103(pSH2)(103 \pm 15$)$ was significantly lower $(P<0.001)$ (Fig. 2$)$. Since FimH, a minor fimbrial subunit, has recently been implicated in promoting bacterial binding to mast cells (20), we examined the degranulating capacity of a mutant strain E. coli ORN103(pUT2002) that expresses type 1 fimbriae that is deficient in FimH. Compared to the mast cell degranulation induced by $E$. coli expressing wild type fimbriae, the FimH ${ }^{-}$mutant evoked only minimal mast degranulation (162 \pm 14$)$. Taken together, these results suggest that the $E$. coli-mediated mast cell degranulation is determined by type 1 fimbriae, and that FimH is the fimbrial subunit responsible for mast cell activation.

Relationship between adherence of type 1 fimbriated E. coli and mast cell degranulation. To determine if $E$. coli-mediated mast cell degranulation can be correlated with the number of adherent bacteria associated with the mast cell surface, we performed a time course experiment of bacterial adherence to mast cells and mast cell degranulation. Freshly isolated mouse peritoneal mast cells were incubated with type 1 fimbriated $E$. coli ORN103 ( pSH2) for various lengths of time, and the bacte- rial adherence and corresponding mast cell degranulation was assessed. Microscopic examination of stained mast cell preparations revealed that there is no preferential site for bacterial adherence on the mast cell surface. Although bacteria appeared randomly distributed on the mast cell, a wide range in the number of adherent bacteria per cell was observed. Examination of crystal violet-stained smears of mast cells exposed to bacteria revealed that mast cells with many adherent bacteria appeared to be fully or partially degranulated (Fig. $3 A$ ), whereas those with few or no adherent bacteria appeared to be replete with granules (Fig. $3 \mathrm{~B}$ ). The time course of bacterial adherence revealed a rapid rate of bacterial adherence in the first $30 \mathrm{~min}$, followed, apparently, by a slower rate of adherence during the next $30 \mathrm{~min}$ (Fig. $4 \mathrm{~B}$ ). It is noteworthy that in light of our recent observation that mast cells are capable of phagocytozing and degrading bacteria (20), it is possible that the number of adherent bacteria detectable by this assay, especially at the later time points, is only a portion of the total adherent bacteria because those bacteria that have been internalized and whose structural integrity are no longer intact will not be detected. The degree of mast cell degranulation induced by $E$. coli ORN103( $\mathrm{pSH} 2)$ after different lengths of time is shown in Fig. $4 \mathrm{~A}$. A $10-20 \%$ loss in fluorescence intensity in the mast cells was noticed immediately upon exposure to bacteria $(0 \mathrm{~min})$, which was then followed by a relatively steady rate of degranulation over the entire 60-min incubation period (Fig. $4 \mathrm{~A}$ ). These results indicate that the adherence of type 1 fimbriated $E$. coli to mast cells followed mast cell degranulation at the early time points. At time points after $30 \mathrm{~min}$, only a small increase in the number of adherent bacteria appeared to be evident, while mast cell degranulation continued incrementally. The comparison of the adherence of nonfimbriated or the FimH $^{-} E$. coli to mast cells and the corresponding state of mast cell degranulation after $60 \mathrm{~min}$ was also examined and found to be relatively low (Fig. $4, A$ and $B$ ). It is noteworthy that during 60 min of incubation with each of the bacterial strains, the viability of the mast cells remained unchanged ( $>90 \%$ viable) as determined by the trypan blue dye exclusion test.

In vivo mast cell degranulation induced by type 1 fimbriated E. coli. Mast cell degranulation in vivo has been previously investigated in various animal models. To demonstrate the physiological relevance of our findings, we developed a mouse model of bacterial peritonitis that is closely based on a previously described model of immune complex-mediated peritonitis $(7,8)$. When the degranulation of mast cells in the mouse peritoneum after $60 \mathrm{~min}$ of injection of $5 \times 10^{6}$ type 1 fimbriated $E$. coli ORN103(pSH2) or nonfimbriated $E$. coli ORN103 was compared, we determined that the mast cells exposed to type 1 fimbriated $E$. coli $(106 \pm 7)$ were significantly lower in fluorescence intensity than cells exposed to nonfimbriated bacteria $(145 \pm 12 ; P<0.05)$ at $60 \mathrm{~min}$ (Fig. 5). The marked difference in the capacity of both strains to cause mast cell degranulation was observed even after $15 \mathrm{~min}$ of exposure to bacteria (Fig. 5). We stained and examined peritoneal mast cells after exposure to type 1 fimbriated $E$. coli for $15 \mathrm{~min}$ and determined that $54 \%$ of them were associated with at least one adherent bacteria. Interestingly, the fluorescence intensity of these mast cells was only marginally more than mast cells exposed to type 1 fimbriated $E$. coli for $60 \mathrm{~min}$, implying that the majority of the mast cell degranulation events in vivo had occurred before the $15 \mathrm{~min}$ interval. These results demonstrate 


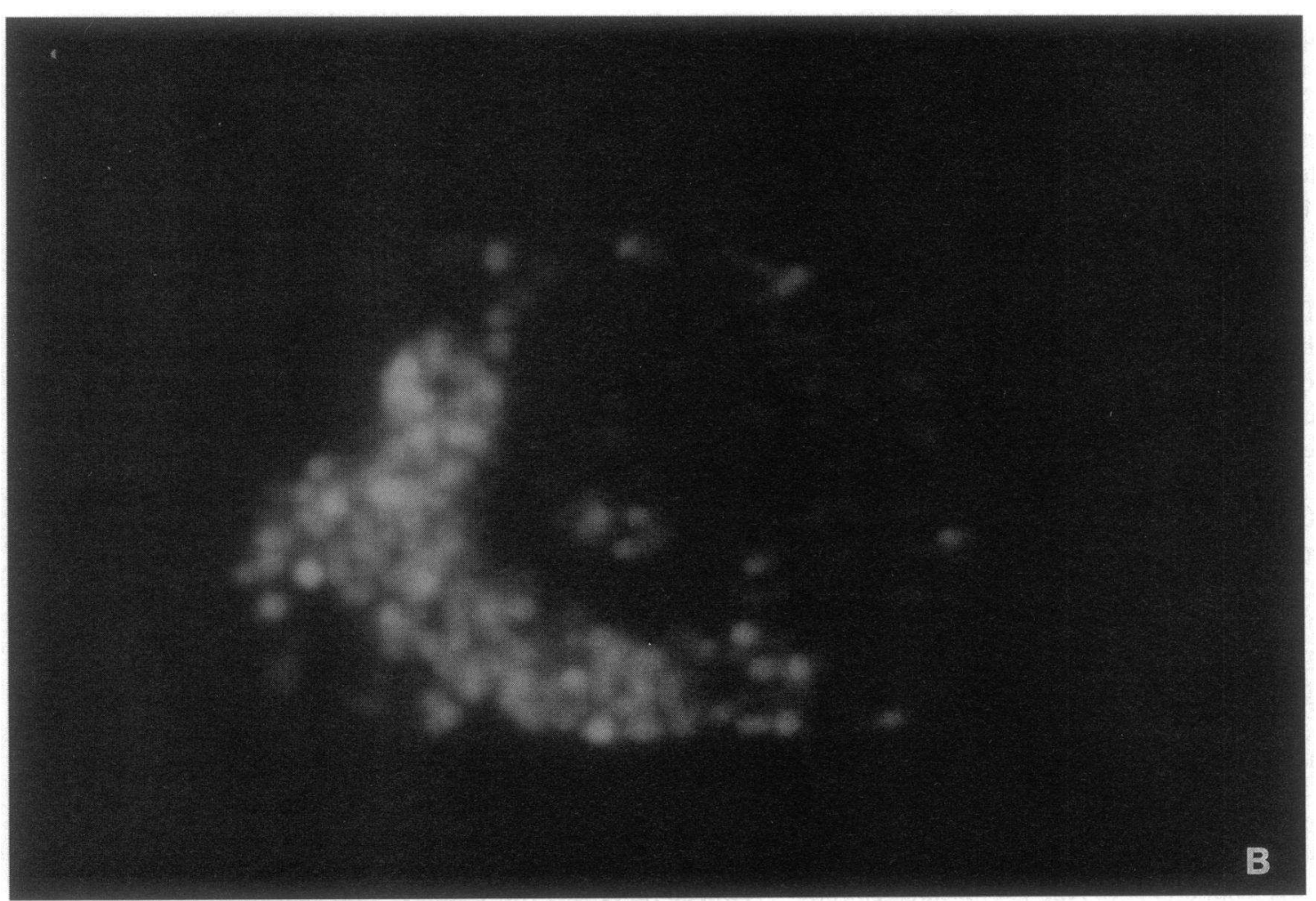

Figure 1. Photographs depicting fluorescence intensity of unstimulated and stimulated mast cells when viewed through an image analysis system. Fluorescence intensity is indicated by different colors, which are not distinguishable in black and white print. Purified peritoneal mast cells were incubated with buffer $(A)$ or $E$. coli ORN103(pSH2) $(B)$ for $60 \mathrm{~min}$ at $37^{\circ} \mathrm{C}$. After which, the incubation mixture was cytospun onto a glass slide and fixed with Carnoy's fixative for $1 \mathrm{~min}$. Cell smears were stained with $6.25 \mu \mathrm{g} / \mathrm{ml}$ avidin-FITC for $2 \mathrm{~h}$, washed with PBS, mounted in phosphate-buffered glycerol containing $30 \mathrm{mM}$ triethelenediamine ( $\mathrm{pH} \mathrm{8.6)}$, and examined by fluorescence microscopy. Note that the majority of mast cells exposed to the nonfimbriated ORN103 or FimH ${ }^{-}$ORN103(pUT2002) E. coli strains also resembled the cell shown in $A$. 


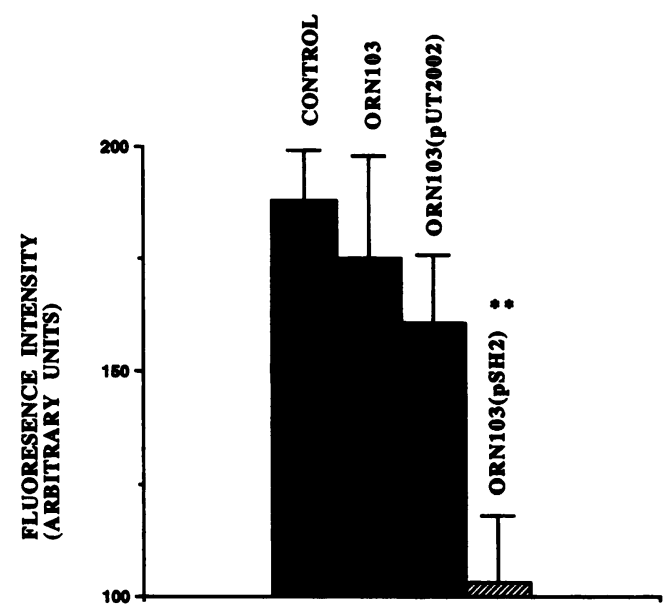

Figure 2. Fluorescence intensity of mast cells exposed to type 1 fimbriated, FimH ${ }^{-}$and nonfimbriated E. coli strains. Purified mast cells were incubated with $4 \times 10^{7} E$. coli ORN103(pSH2), E. coli ORN103(pUT2002), E. coli ORN103, or buffer alone for $60 \mathrm{~min}$ at $37^{\circ} \mathrm{C}$. Cytospun smears of the incubation mixtures were stained with avidin-FITC and evaluated for mast cell fluorescence as indicated in Fig. 1. Mean fluorescence intensity of 50-100 mast cells was determined and expressed in arbitrary units. The data is represented as mean \pm SEM, $n=$ four to seven experiments. ${ }^{* *} P<0.001$ compared to control, E. coli ORN103 or E. coli ORN103(pUT2002).

that type 1 fimbriae of $E$. coli exhibit a capacity to induce mast cell degranulation in vivo, but in addition, suggest that the rate of mast cell degranulation in vivo was appreciably more rapid than in vitro.

Since type 1 fimbriae are characterized by their ability to bind mannose-containing compounds, we investigated the effect of the mannose analogue MMP in inhibiting mast cell degranulation induced by type 1 fimbriated $E$. coli. Mast cell degranulation was assessed after type 1 fimbriated $E$. coli suspended in $200 \mathrm{mM}$ MMP were injected into the peritoneum of mice. A significant difference in fluorescence intensity of mast cells exposed to $E$. coli ORN103(pSH2) for $60 \mathrm{~min}$ in the presence and absence of the mannose analogue was observed. The fluorescence intensity of mast cells exposed to type 1 fimbriated $E$. coli in the absence of the inhibitor was $106 \pm 8$, whereas in the presence of the inhibitor it was $141 \pm 25$ (Fig. 5). This finding indicates that the putative receptor analogue for type 1 fimbriae was capable of inhibiting mast cell degranulation in vivo. It is not known why there is a high variability in fluorescence intensity of mast cells exposed simultaneously to bacteria and the inhibitor; however, one possibility is that the high concentration of MMP was not uniformly sustainable in the mouse peritoneum for the entire duration of the experiment. We used the well-known mast cell activator compound $48 / 80$ to show that MMP has no inhibitory effect on mast cell degranulation per se (Fig. 5).

FimH-mediated histamine release by mast cells in vivo. To support our morphological studies of mast cell degranulation, we examined the peritoneal fluids of mice exposed to type 1 fimbriated, FimH ${ }^{-}$, and nonfimbriated $E$. coli for released histamine. Histamine is a prominent extracellular product of mast cell degranulation and a potent inflammatory mediator. As is evident from Fig. 6, significantly higher levels of histamine $(290 \pm 60 \mathrm{ng})$ were detected in mice injected with type 1
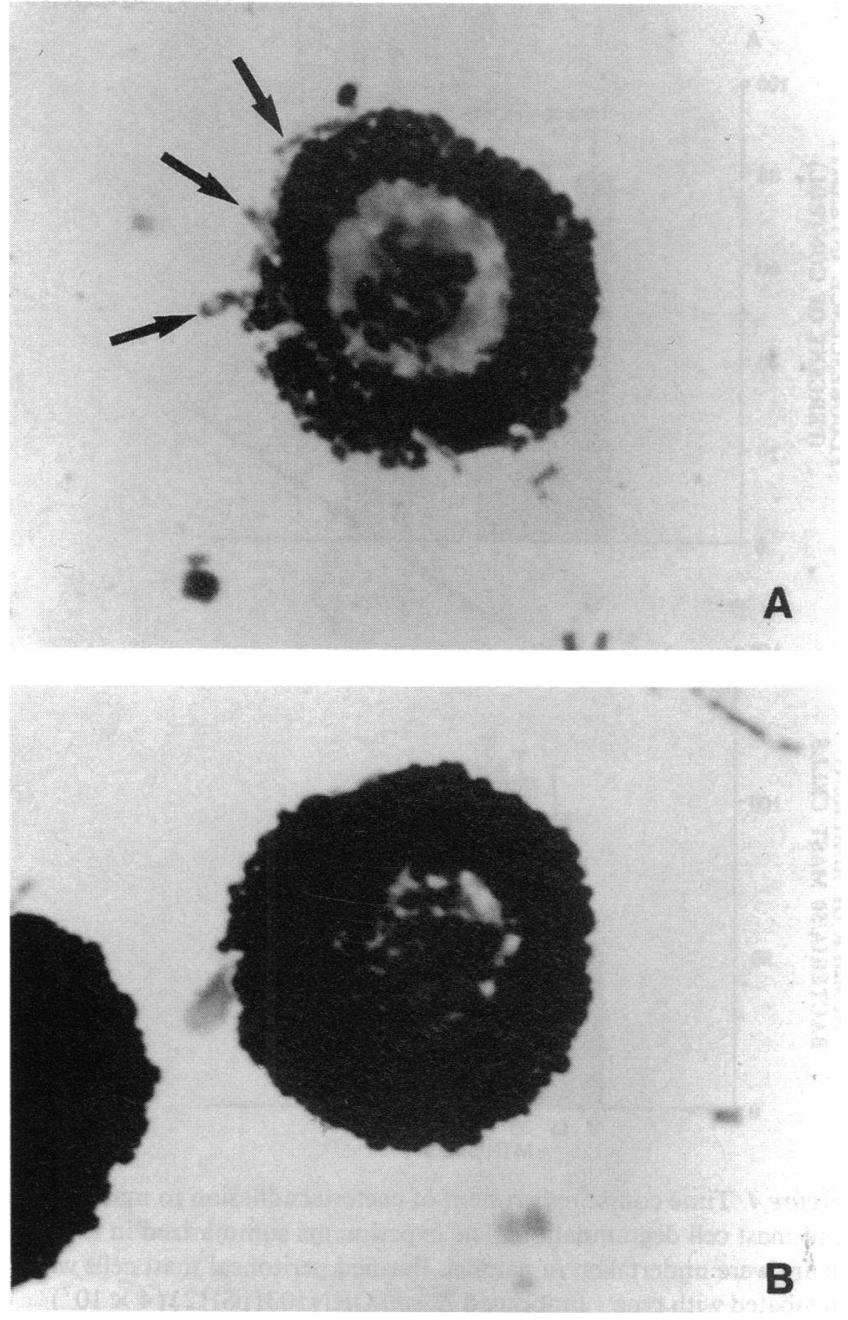

Figure 3. Photomicrographs showing mast cells exposed to type 1 fimbriated $E$. coli ORN103(pSH2). Typically, mast cells with few or no adherent bacteria appeared fully granulated $(B)$, whereas mast cells with many adherent bacteria appeared completely or partially degranulated $(A)$. Arrows, adherent bacteria. Mast cell preparations were made as indicated in Fig. 2 and stained with crystal violet and viewed by light microscopy.

fimbriated E. coli ORN103(pSH2) compared to mice injected with either the $\mathrm{FimH}^{-}$mutant $E$. coli ORN103(pUT2002) $(55.0 \pm 29 \mathrm{ng} ; P<0.001)$ or nonfimbriated $E$. coli ORN103 $(44 \pm 30 \mathrm{ng} ; P<0.001)$. These results indicate that $E$. coli type 1 fimbriae-mediated mast cell degranulation in vivo correlated with the presence of released histamine in the peritoneal fluid, and further, that removal of FimH from E. coli impairs its ability to trigger histamine release from mast cells.

To confirm the notion that FimH is the determinant responsible for triggering histamine release, we examined the ability of isolated FimH to induce histamine release from mast cells. We recently reported the stabilization and isolation of relatively large amounts of recombinant FimH from E. coli (15). Since soluble FimH molecules are not efficient activators of mast cells (data not shown) possibly because of their monomeric state, it was necessary to first immobilize FimH onto inert beads before testing their stimulatory activity. Inert beads coated with FimH were potent activators of mast cell histamine 


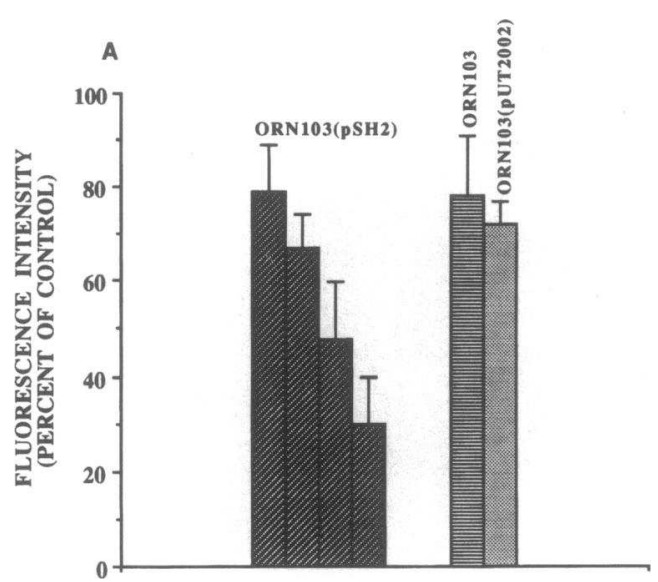

B

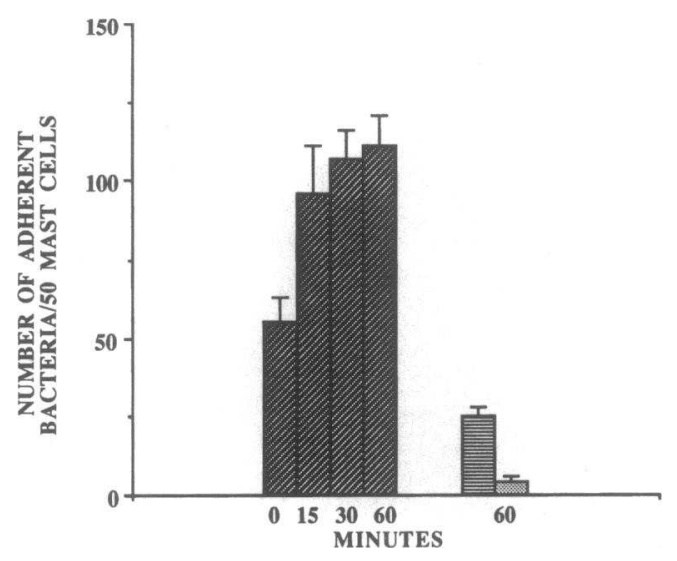

Figure 4. Time course experiment of bacterial adhesion to mast cells and mast cell degranulation. The experiments summarized in this figure were undertaken in parallel. Purified peritoneal mast cells were incubated with type 1 fimbriated E. coli ORN103( pSH2) $\left(4 \times 10^{7}\right)$ at $37^{\circ} \mathrm{C}$ for increasing periods of time. Control cells were incubated with buffer alone. At appropriate times, two sets of cytospun smears of the incubation mixture were prepared and fixed with Carnoy's fixative. To determine degree of mast cell degranulation, one set of smears were stained as indicated in Fig. 1. The mean fluorescence intensity of 50-100 mast cells was determined, and the results are expressed as percent of control $(A)$. To determine the adherence of bacteria to mast cells, the second set of smears were stained with crystal violet and viewed by light microscopy. About 200 mast cells were examined for adherent bacteria and the results are expressed as number of adherent bacteria per 50 mast cells $(B)$. For comparative purposes, the adherence of the FimH ${ }^{-}$mutant ORN103(pUT2002) and the nonfimbriated ORN103 E. coli strains to mast cells after 60 min of incubation and the corresponding fluorescence intensity of these mast cells is also shown. The results are expressed as mean $\pm \mathrm{SEM} ; n=$ three to four experiments for all assays.

release, and interestingly, the amount of histamine generated ( $316 \pm 16 \mathrm{ng}$ ) was comparable to the level generated by type 1 fimbriated $E$. coli ORN103(pSH2) (Fig. 6). Furthermore, the presence of $200 \mathrm{mM}$ MMP partially neutralized the capacity of the FimH beads to cause mast cell release of histamine $(183 \pm 11 ; P<0.05)$. As an additional control for the specificity of the FimH-mediated reaction, we tested the ability of inert beads coated with FimA, the major subunit of type 1 fimbriae, to elicit histamine release. The amount of histamine released in the mouse peritoneum by the injection of isolated FimA ( $43 \pm 9$

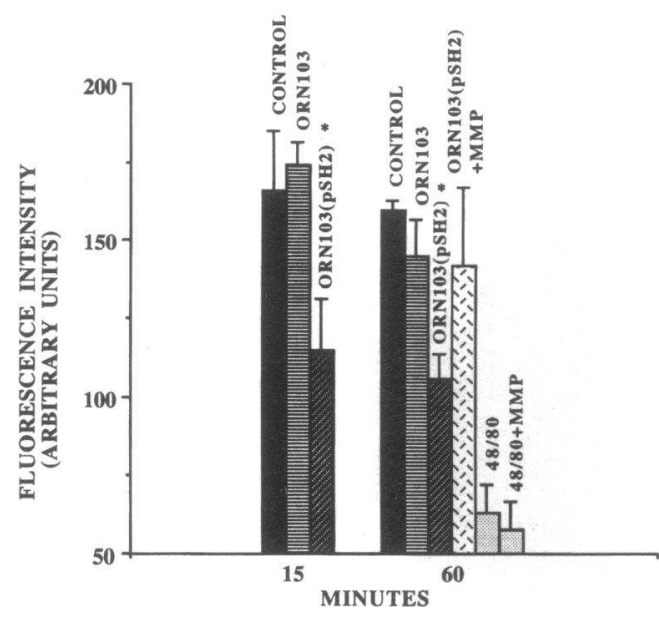

Figure 5. Mast cell degranulation in vivo induced by type 1 fimbriated bacteria. $5 \times 10^{6}$ type 1 fimbriated $E$. coli ORN103(pSH2) or non fimbriated $E$. coli ORN103 or $3 \mu \mathrm{g}$ of compound $48 / 80$ were injected into the peritoneal cavities of mice. Control animals were injected with PBS. After $15 \mathrm{~min}$ or $60 \mathrm{~min}$, peritoneal cells were harvested by lavage and prepared as indicated in Fig. 1. To determine the inhibitory effect of MMP on mast cell degranulation, $E$. coli ORN103(pSH2) or compound $48 / 80$ were injected into the mouse peritoneum in the presence of $200 \mathrm{mM}$ MMP. The fluorescence intensity of 50-100 mast cells/mouse was evaluated and is expressed in arbitrary units. The data represent mean $\pm \mathrm{SEM}, n=$ three to five mice. ${ }^{*} P<0.05$ compared to control and $E$. coli ORN103 at the corresponding time point.

ng) was minimal and comparable to the amount released when the $\mathrm{FimH}^{-}$mutant $E$. coli ORN103(pUT2002) was used as the stimulant.

We also compared the nature of the inflammatory response induced in mice by the injection of FimH beads with the response evoked by type 1 fimbriated $E$. coli by examining the composition of the cell population in the peritoneal lavage of the two groups of mice $60 \mathrm{~min}$ after challenge. The percent ratio of mast cells/neutrophils/monocytes and lymphocytes in the peritoneum of mice injected with FimH beads was $4 \pm 1$ : $17 \pm 5: 79 \pm 6$, respectively, while this ratio in mice injected with type 1 fimbriated $E$. coli was $7 \pm 1: 15 \pm 1: 78 \pm 2$. The corresponding ratio in untreated control mice was $9 \pm 2: 7 \pm 2: 83 \pm 5$. This finding suggests that both FimH and type 1 fimbriated $E$. coli caused a marked but comparable increase in the population of neutrophils in the peritoneal cavity.

\section{Discussion}

Although mast cells are known primarily for their role in mediating hypersensitivity reactions against various allergens through the release of inflammatory mediators, their precise functional role(s) in the host has been the subject of considerable speculation. In this study, we propose a role for mast cells in mediating inflammation against bacteria. This notion is based on our finding that mast cells have the capacity to recognize and be activated by type 1 fimbriated $E$. coli. A correlation was observed between bacterial adherence to mast cells and the degranulation of these cells in the initial period of the interaction, indicating that mast cell release of inflammatory mediators can be triggered by the adherence of bacteria to its surface. Mast cell degranulation induced by $E$. coli expressing type 1 


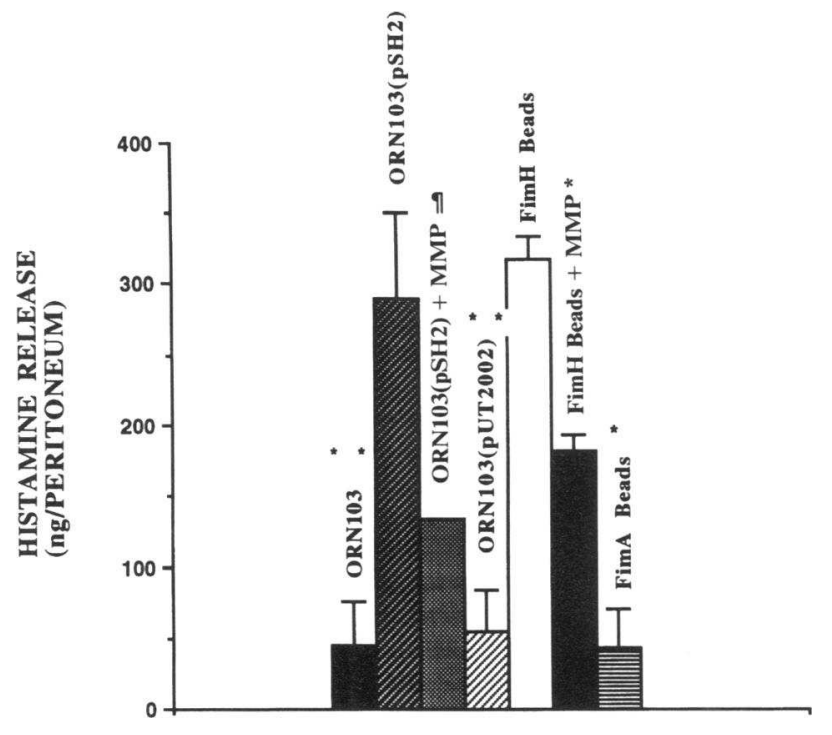

Figure 6. Histamine release triggered by type 1 fimbriated $E$. coli and FimH beads in the mouse peritoneum. ORN103(pSH2), ORN103(pUT2002), or ORN103 E. coli strains or FimH- or FimAcoated beads were injected into the peritoneal cavities of different groups of mice. After $60 \mathrm{~min}$, the peritoneal fluids were collected, and after peritoneal cells were removed by centrifugation, they were assayed for histamine by a fluorimetric method using $\alpha$-phthalaldehyde. To determine the effect of MMP on type 1 fimbriae-or FimH-induced histamine release, E. coli ORN103(pSH2) or FimH beads were injected into the mouse peritoneum in the presence of $200 \mathrm{mM}$ MMP. The values are expressed as net release (stimulated release unstimulated release). The mean spontaneous release was $295 \pm 34$ $\mathrm{ng} /$ peritoneum. The results are expressed as mean $\pm \mathrm{SEM} ; n=$ three to five mice (' $n=$ two mice). ${ }^{*} P<0.05$ compared to FimH-coated beads; ${ }^{* *} P<0.001$ compared to $E$. coli ORN103(pSH2).

fimbriae was also demonstrated in vivo in a mouse model of bacterial peritonitis. In this model, injection of $E$. coli into the mouse peritoneum resulted in significant degranulation of mast cells that was correlated with increased levels of histamine in the peritoneal cavities of the mice. This study supports the findings of Church et al. (9), who demonstrated the release of histamine by mast cells obtained from the lungs and tonsils of humans by formalin killed $E$. coli in vitro. Although the mechanism of mast cell activation by $E$. coli was not fully investigated, these authors did observe a $30 \%$ inhibition of E. coli-induced histamine release by sugars that suggested that the interaction involved a lectin-mediated mechanism. In this study, the sensitivity of mast cell degranulation caused by type $1 \mathrm{fim}$ briated $E$. coli to MMP also suggested a lectin based interaction. The lectin appears to be FimH, which is borne on fimbriae protruding from the bacterial surface and the complementary sugar is presumably located on the plasma membrane of the mast cell. However, in light of the recent report that D-mannose analogues can block the binding of type 1 fimbriated bacteria to nonglycosylated compounds (30), it cannot be readily assumed that the putative FimH receptor is a mannosylated compound. Our finding that fimbriae mediate mast cell degranulation is also consistent with the findings of Scheffer et al. $(10,31)$. Although these investigators did not directly demonstrate mast cell degranulation by $E$. coli fimbriae, they have nevertheless indicated that these organelles potentiated hemolysin-induced histamine release from mast cells.
Our finding implicating type 1 fimbriae of $E$. coli in mast cell degranulation is consistent with the notion that fimbriae not only promote bacterial colonization of mucosal cells, but they also play a crucial role in regulating the host's inflammatory and immunologic processes once the host's integumental barrier has been breached (32). Recently, type 1 fimbriae of $E$. coli have been shown to initiate human B lymphocyte proliferation and secretion of IgM antibody (14), as well as modulate neutrophil activation and secretion of various oxygen radicals (15). By the use of genetically well-defined recombinant $E$. coli strains, we have definitively demonstrated that mast cells are activated by type 1 fimbriae, and by demonstrating the activity of the isolated protein, we have implicated $\mathrm{FimH}$, a minor fimbrial subunit, as the determinant on type 1 fimbriae responsible for mast cell activation.

Mast cell degranulation can be caused by various immunological and nonimmunological agents. The mechanism of degranulation induced by these stimulants varies considerably with the characteristics of the stimulant. For example, IgE/antigen-induced mast cell secretion is a controlled mechanism that is terminated within $2-5 \min (9,33,34)$, whereas ionophore-induced mast cell secretion is more sustained and continues for periods of $\leq 10 \mathrm{~min}(34,35)$. E. coli-induced mast cell degranulation is characterized by an incremental release of mediators that is sustained $\leq 60 \mathrm{~min}$. This distinct pattern of degranulation corresponds to the pattern observed previously by Church et al. (9) when they studied histamine release by mast cells exposed to formalin killed $E$. coli. It is interesting that mast cell degranulation correlated with bacterial adherence at the initial time points of incubation; however, it was not possible to determine if this relationship continued at later time points because of the difficulty in detecting bacteria that had been phagocytozed and degraded. It is conceivable that the intracellular cytoskeletal movements associated with bacterial phagocytosis also contributed to the process of mast cell degranulation. It is noteworthy that both mast cell degranulation and bacterial phagocytosis were initiated by the binding of bacterial FimH to the mast cell membrane, indicating that a common receptor(s) and signaling pathway may be involved. There is currently no information on the nature of the putative FimH receptor on mast cells.

Although we have observed significant mast cell degranulation after the injection of type 1 fimbriated bacteria into the peritoneal cavities of mice, and we have noted that the majority of these degranulated mast cells were associated with at least one adherent bacteria, we cannot assume that the mast cell degranulation seen in vivo is entirely the consequence of direct contact with type 1 fimbriated bacteria. A number of alternate mechanisms where type 1 fimbriated $E$. coli can effect mast cell degranulation without contact with mast cells do exist. One mechanism could involve bacterial activation of the complement pathway where byproducts such as $\mathrm{C} 3 \mathrm{a}$ and $\mathrm{C5a}$, degranulate mast cells (36-38). Another mechanism of mast cell degranulation could involve secreted products of activated macrophages and neutrophils, such as HRA-N or band-2 protein, which can induce mast cell degranulation $(39,40)$. Our finding that most of the peritoneal mast cells were degranulated only $15 \mathrm{~min}$ after the injection of type 1 fimbriated bacteria argues against secreted products of recruited neutrophils triggering mast cell degranulation because it takes $>15 \mathrm{~min}$ for this process to occur. However, we are unable at this time to 
rule out the effect of products of activated peritoneal macrophages and of complement activation, both of which can be generated as early as $5 \mathrm{~min}$ after introduction of the stimulating agent (41). Indeed, our observation that the rate of mast cell degranulation in vivo was appreciably faster than the rate at which adherent bacteria were capable of triggering mast cell degranulation in vitro suggests that certain host factors were also contributing to mast cell degranulation. This notion is further supported by the observation that relatively fewer numbers of type 1 fimbriated bacteria were apparently required to induce mast cell degranulation in vivo than in vitro. Although no specific effort to optimize the concentration of ORN103(pSH2) required for mast cell degranulation in either the in vitro or in vivo assays was made, we have determined that a bacteria/mast cell ratio of $50: 1$ is required to evoke appreciable mast cell degranulation in vitro, whereas the bacte$\mathrm{ria} /$ mast cells ratio required to achieve mast cell degranulation in vivo was estimated to be only $3: 1$. This estimated ratio is based on the fact that we used $5 \times 10^{6} \mathrm{E}$. coli ORN103( $\left.\mathrm{OSH} 2\right)$, and that the mouse peritoneum contained $\sim 3-4 \times 10^{7}$ cells of which $\sim 5 \%\left(1.5 \times 10^{6}\right)$ were mast cells. This ratio is probably an overestimation, considering the large number of peritoneal cells other than mast cells to which the $E$. coli are likely to bind. Hence, it is probable that the actual number of bacteria available to directly bind mast cells in the mouse peritoneum are only a small fraction of the injected bacteria. Taken together, we suggest that direct binding of type 1 fimbriated bacteria to mast cells cause mast cell degranulation in vivo; however, other host factors may also contribute to this process.

The extensive degranulation of mast cells in the mouse peritoneum induced by type 1 fimbriated bacteria (Fig. 5) implied a substantial release of inflammatory mediators including histamine. However, the amounts of histamine detected (Fig. 6) are markedly lower than expected. This observation is attributed to the rapid degradation of histamine in the body (5). Thus, rather than reflecting the total amount of histamine released during the entire incubation period, the histamine assay represents only recently released histamine. Mast cells are a major source of histamine in the body, and FimH triggered mast cell release of histamine, in concert with other mast cell products such as leukotrienes and cytokines, is likely to significantly impact on bacterial survival at the site of inflammation. Among other effects, histamine can induce vascular permeability (41) and expression of the endothelial leukocyte adhesion molecule-1 $(42,43)$, which indirectly facilitate recruitment of neutrophils to the site of inflammation resulting in early elimination of the bacteria. Thus, because of their capacity to recognize and bind to specific components on bacterial surfaces, their prominent presence at the host-environment interface, and their capacity to release potent mediators of inflammation such as histamine, mast cells are likely to play a crucial role in modulating host defense against pathogenic bacteria.

\section{Acknowledgments}

We wish to thank Mrs. Vourdonna Knoeppel for secretarial assistance, Mr. Robert Henry for photography, and Dr. Sandhya Jaiswal for assistance on a number of experiments. We thank Dr. Alice P. Pentland of the Department of Dermatology for providing the facilities for performing histamine assays.

This work was supported by the National Institutes of Health (AI 13550), Monsanto-Searle/Washington University Biomedical Program, and Searle (Arthritis and Prostaglandin Research Challenge).

\section{References}

1. Galli, S. J. 1993. New concepts about the mast cell. N. Engl. J. Med. 328:257-263.

2. Galli, S. J., and Y. Kitamura. 1987. Animal model of human disease. Genetically mast-cell-deficient $\mathrm{W} / \mathrm{W}^{\mathrm{v}}$ and $\mathrm{S} 1 / \mathrm{S} 1^{\mathrm{d}}$ mice. Their value for the analysis of the roles of mast cells biologic responses in vivo. Am. J. Pathol. 127:191-198.

3. Wershil, B. K., T. Murakami, and S. J. Galli. 1988. Mast cell-dependent amplification of an immunologically nonspecific inflammatory response. Mast cells are required for the full expression of cutaneous acute inflammation induced by phorbol 12-myristate-13-acetate. J. Immunol. 140:2356-2360.

4. Yano, H., B. K. Wershill, N. Arizono, and S. J. Galli. 1989. Substance $P$-induced augmentation of cutaneous vascular permeability and granulocyte infiltration in mice is mast cell dependent. J. Clin. Invest. 84:1276-1286.

5. Ramos, B. F., R. Qureshi, K. M. Olsen, and B. A. Jakschik. 1990. The importance of mast cells for the neutrophil influx in immune complex-induced peritonitis in mice. J. Immunol. 145:1868-1873.

6. Zhang, Y., B. F. Ramos, and B. A. Jakschik. 1991. Augmentation of reverse arthus reaction by mast cells in mice. J. Clin. Invest. 88:841-846.

7. Ramos, B. F., Y. Zhang, R. Qureshi, and B. A. Jakschik. 1991. Mast cells are critical for the production of leukotrienes responsible for neutrophil recruitment in immune complex-induced peritonitis in mice. J. Immunol. 147:16361641 .

8. Zhang, Y., B. F. Ramos, and B. A. Jakschik. 1992. Neutrophil recruitment by tumor necrosis factor from mast cells in immune-complex peritonitis. Science (Wash. DC). 258:1957-1959.

9. Church, M. K., S. Norn, G. J.-K. Pao, and S. T. Holgate. 1987. Non-IgE-dependent bacteria-induced histamine release from human lung and tonsillar mast cells. Clin. Allergy. 17:341-353.

10. Scheffer, J., K. Vosbeck, and W. Konig. 1986. Induction of inflammatory mediators from human polymorphonuclear granulocytes and rat mast cells by haemolysin-positive and -negative $E$. coli strains with different adhesions. Immunology. 59:541-548.

11. Abraham, S. N., D. Sun, J. B. Dale, and E. H. Beachey. 1988. Conservation of the D-mannose-adhesion protein among type 1 fimbriated members of the family Enterobacteriaceae. Nature (Lond.). 336:682-684.

12. Ofek, I., and E. H. Beachey, editors. 1980. In Bacterial Adherence, Receptor Recognition, Series B, Vol. 6. Chapman \& Hall, London. 1-29.

13. Clegg, S., and G. F. Gerlach. 1987. Enterobacterial fimbriae. J. Bacteriol. 169:934-938.

14. Ponniah, S., S. Abraham, and R. O. Endres. 1992. T-cell-independent stimulation of immunoglobulin secretion in resting human $B$ lymphocytes by the mannose-specific adhesion of Escherichia coli type 1 fimbriae. Infect. Immun. 60:5197-5203.

15. Tewari, R., J. I. MacGregor, T. Ikeda, J. R. Little, S. J. Hultgren, and S. N. Abraham. 1993. Neutrophil activation by nascent FimH subunits of type 1 fimbriae purified from the periplasm of Escherichia coli. J. Biol. Chem. 268:30093015 .

16. Abraham, S. N., J. D. Goguen, D. Sun, P. Klemm, and E. H. Beachey. 1987. Identification of two ancillary subunits of Escherichia coli type 1 fimbriae by using antibodies against synthetic oligopeptides of fim gene products. J. Bacteriol. 169:5530-5535.

17. Maurer, L., and P. E. Orndorff. 1987. Identification and characterization of genes determining receptor binding and pilus length of Escherichia coli type 1 pili. J. Bacteriol. 169:640-645.

18. Hansen, M. S., and C. C. Brinton. 1988. Identification and characterization of $E$. coli type 1 pilus tip adhesion protein. Nature (Lond.). 332:265-268.

19. Klemm, P., and G. Christiansen. 1987. Three fim genes required for the regulation of length and mediation of adhesion of Escherichia coli type 1 fimbriae. Mol. \& Gen. Genet. 208:439-445.

20. Malaviya, R., E. A. Ross, J. I. MacGregor, T. Ikeda, J. R. Little, B. A. Jakschik, and S. N. Abraham. 1994. Mast cell phagocytosis of FimH expressing enterobacteria. J. Immunol. In press.

21. Orndorff, P. E., and S. Falkow. 1984. Organization and expression of genes responsible for type 1 piliation in Escherichia coli. J. Bacteriol. 159:736744.

22. Hull, R. A., R. E. Gill, P. Hsu, B. H. Minshew, and S. Falkow. 1981 Construction and expression of recombinant plasmids encoding type 1 or D-mannose-resistant pili from a urinary tract infection Escherichia coli isolate. Infect. Immun. 33:933-938.

23. Minion, F. C., S. N. Abraham, E. H. Beachey, and J. D. Goguen. 1986. The genetic determinant of adhesive function in type 1 fimbriae of Escherichia coli is distinct from the gene encoding the fimbrial subunit. J. Bacteriol 165:1033-1036.

24. Jones, C. H., J. S. Pinkner, A. Nicholes, L. N. Slonim, J. Heuser, S. N. Abraham, and S. J. Hultgren. 1993. Invariant residues in the conserved chaperone cleft are essential for the assembly of the composite type 1 pilus fiber. Proc. Natl. Acad. Sci. USA. 90:8397-8401. 
25. Abraham, S. N., D. L. Hasty, W. A. Simpson, and E. H. Beachey. 1983. Antiadhesive properties of a quaternary structure-specific hybridoma antibody against type 1 fimbriae of Escherichia coli. J. Exp. Med. 158:1128-1144.

26. Sterk, A. R., and T. Ishizaka. 1982. Binding properties of IgE receptors on normal mouse mast cells. J. Immunol. 128:838-843.

27. Bergstresser, P. R., R. E. Tigelaar, and M. D. Tharp. 1984. Conjugated avidin identifies cutaneous rodent and human mast cells. J. Invest. Dermatol. 83:214-218.

28. Tharp, M. D., L. L. Seelig, Jr., R. E. Tigelaar, and P. R. Bergstresser. 1985. Conjugated avidin binds to mast cell granules. J. Histochem. Cytochem. 33:2732.

29. Shore, P. A., A. Burkhalter, and Y. H. Colen. 1959. A method for the fluorometric assay of histamine in tissue. J. Pharmacol. Exp. Ther. 127:182-186.

30. Sokurenko, E. V., H. S. Courtney, S. N. Abraham, P. Klemm, and D. L.

Hasty. 1992. Functional heterogeneity of type 1 fimbriae of Escherichia coli. Infect. Immun. 60:4709-4719.

31. Scheffer, J., W. Konig, J. Hacker, and W. Goebel. 1985. Bacterial adherence of hemolysin production from Escherichia coli induces histamine and leukotriene release from various cells. Infect. Immun. 50:271-278.

32. Hoepelman, A. I., and E. I. Tuomanen. 1992. Consequence of microbial attachment: directing host cell functions with adhesion. Infect. Immun. 60:17291733.

33. Ishizaka, T., and K. Ishizaka. 1984. Activation of mast cells by mediator release through IgE receptors. Proc. Allergy. 34:188-235.

34. Church, M. K., G. J.-K. Pao, and S. T. Holgate. 1982. Characterization of histamine secretion from mechanically dispersed human lung mast cells: effects of anti-IgE, calcium ionophore A23187, compound 48/80, and basic polypeptides. J. Immunol. 129:2116-2121.
35. Siraganian, R. P., A. Kulczycki, Jr., G. Mendoza, and H. Metzger. 1975. Ionophore A-23187 induced histamine release from rat mast cells and rat basophil leukemia (RBL-1) cells. J. Immunol. 115:1599-1602.

36. Goldstein, I. M. 1988. Complement: biologically active products. In Inflammation: Basic Principles and Clinical Correlates. J. I. Gallin, I. M. Goldstein, and R. Snyderman, editors. Raven Press Ltd. New York. pp. 55-61.

37. Johnson, A. R., T. E. Hugli, and H. J. Muller-Eberhard. 1975. Release of histamine from rat mast cells by complement peptides $\mathrm{C} 3 \mathrm{a}$ and $\mathrm{C} 5 \mathrm{a}$. Immunology. 28:1067-1080.

38. Kajita, T., and T. E. Hugli. 1991. Evidence for in vivo degradation of C3a anaphylatoxin by mast cell chymase. Am. J. Pathol. 138:1359-1369.

39. White, M. V., and M. A. Kaliner. 1987. Neutrophils and mast cells. I. Human neutrophil-derived histamine-releasing activity. J. Immunol. 139:16241630.

40. Ranadive, N. S., and C. G. Cochrane. 1971. Mechanism of histamine release from mast cells by cationic protein (band 2) from neutrophil lysosomes. J. Immunol. 106:506-516.

41. Ramos, B. F., Y. Zhang, and B. A. Jakschik. 1994. Neutrophil elicitation in the reverse passive arthus reaction: complement-dependent and -independent mast cell involvement. J. Immunol. 152:1380-1384.

42. Grega, G. J., and Adamski, S. W. 1991. Effects of local mast cell degranulation on vascular permeability to macromolecules. Microcirc. Endothelium Lym phatics 7:267-291.

43. Klein, L. M., R. M. Lavker, W. L. Matis, and G. F. Murphy. 1989. Degranulation of mast cells induces an endothelial antigen central to leukocyte adhesion. Proc. Natl. Acad. Sci. USA. 86:8972-8976. 